\title{
Clinical Profile and Outcome of Adult COVID-19- related Consults at the University of the Philippines- Philippine General Hospital Emergency Department
}

\author{
Scarlett Mia S. Tabuñar, MD, MHA ${ }^{1}$ and Ronald Allan A. Magsino, MD² \\ ${ }^{1}$ Department of Emergency Medicine, College of Medicine and Philippine General Hospital, University of the Philippines Manila \\ ${ }^{2}$ Department of Emergency Medicine, Philippine General Hospital, University of the Philippines Manila
}

\begin{abstract}
Background. Scarcity of early local clinical data of COVID-19 proved to be a major challenge as its course rapidly evolved over time. The information gathered from this study can be used in improving awareness and understanding a novel disease particularly in detecting demographic trends, vulnerable clinical profiles and potential clusters in order to be abreast on how the virus behaves in the local setting.
\end{abstract}

Objectives. 1) To describe the clinical profile of COVID-19 adult consults at the University of the PhilippinesPhilippine General Hospital (UP-PGH) during the early months of the outbreak 2) To determine their association with the COVID-19 results and final outcome

Methods. A retrospective medical record review was done on COVID-19-related consults of patients aged 19 years and above from 01 January to 30 June 2020 at the emergency department (ED). Statistical analyses were done using Chi-squared and Fisher's exact test using STATA V15.1 with 95\% level of significance $(p<0.05)$.

Results. The median age of the 901 COVID-19-related consults at the ED was 46 years; $55.49 \%$ were males mostly belonging to the age group below 60 years. Almost all were Filipinos (99.44\%), majority residing in the city of Manila (64.93\%) and only $2.22 \%$ had a history of travel outside the country. The most common chief complaint was fever (32.47\%) followed by cough (27.58\%) and shortness of breath (25.75\%). Most had their onset of symptoms from 1-7 days $(79.80 \%)$ before ED arrival and $86.07 \%(n=210)$ were COVID-positive after performing the confirmatory test. Patients with confirmed COVID-19 mostly resided in cities of the National Capital Region $(p=0.046)$, either presented with fever or asymptomatic but with exposure to COVID patients (Fisher's Exact test; $p<0.001$ ) and onset of symptoms was 4-5 days $(p=0.007)$. Those identified with poor prognosis were those aged 60 years and older $(p<0.001$ ), with complaint of shortness of breath (Fisher's exact test; $p<0.001$ ) and with delayed symptom presentation of 6 days or more $(p=0.037)$.

Conclusion. The COVID-19-related consults at UP-PGH during the first 6 months of the pandemic were mostly males, Filipinos, belonging to the less than 60 years age group (median age $=46$ years), residing in the city of Manila and no history of travel outside the country. The most common presenting complaint was fever and onset of symptoms was typically 1-7 days before ED arrival. The positive RT-PCR result was significantly associated to patients residing in Metro Manila, either presenting with fever or no symptoms but with exposure to COVID patients, and with onset of symptoms of 4-5 days. Older age (60 years old and above), shortness of breath and delayed symptom presentation of 6 days of more were also found to have significant association with poor prognosis. As not much is known of the behavior and course of COVID-19 particularly at the local setting, it is therefore crucial to be aware of emerging trends to respond adequately and achieve optimal outcomes.

Key Words: COVID-19, epidemiology, emergency department, UP-PGH

Corresponding author: Scarlett Mia S. Tabuñar, MD, MHA

Department of Emergency Medicine, Philippine General Hospital

University of the Philippines Manila

Taft Avenue, Ermita, Manila 1000, Philippines

Email: sstabunar@up.edu.ph 


\section{INTRODUCTION}

Since the first detected cluster of novel coronavirus cases in late December 2019 at Wuhan, Hubei, China, ${ }^{1}$ healthcare systems worldwide have been under tremendous pressure due to the surge of patients and the resulting unprecedented clinical demand. The World Health Organization (WHO) on 30 January 2020 declared the novel coronavirus outbreak as a public health emergency of international concern due to the sharp increase in affected individuals. Thereafter, subsequent turn of events showed the rapid spread of the infections and on 11 March the public health crisis resulting from this newly named disease, COVID-19, was declared a pandemic. ${ }^{2,3}$

In the Philippines, confirmation of local transmission in March led to the implementation of the enhanced community quarantine (ECQ) wherein restrictions on mobility, ban of public events and gatherings, closure of schools, shutting down of non-essential businesses and social distancing were enforced in an effort to curb the threats brought about by COVID-19. Building from the previous experience of SARS outbreak in 2002-03 which spread to 29 countries worldwide ${ }^{4,5}$ and MERS-CoV in Middle Eastern countries in $2012^{6}$ the immediate response of the medical community against COVID-19 includes analyses of epidemiologic data to heighten situational awareness and initiate timely interventions. ${ }^{7}$ The University of the Philippines-Philippine General Hospital (UP-PGH), a tertiary hospital located in the center of the city of Manila which is seeing an average of 150 emergency consults per day, has been beefing up its capability to address the impending influx of patients presenting with the novel coronavirus symptoms as early as mid-January 2020. Clinical algorithms were drafted to manage patients presenting with fever, respiratory symptoms and history of travel to countries with reported COVID-19 cases or exposure to positive patients. Screening guidelines were primarily steered by clinical characteristics seen and described in patients in China, but local data on the clinical features of COVID-19 patients back then were initially very scarce. The emergency department (ED) is the entry point of patients to any hospital facility; it is at a strategic position to pick up and detect any emerging trend or infectious cluster in the community. Being the first contact area, it is worth analyzing the characteristics of COVID-related consults since they can provide a rich clinical data bed about COVID-19. These are particularly pivotal for they can be used as guides by emergency physicians, infectious specialists and hospital administrators as they establish the baseline course of an unknown deadly virus. It is, therefore, the aim of this study to describe the clinical profile of COVID-19-related consults at UP-PGH and their association to COVID results and final outcome during the early phase of the disease when very little was known about it.

\section{MATERIALS AND METHODS}

A retrospective cohort study was conducted through medical record review covering a 6-month period from 01 January-30 June, 2020 of adult (age 19 years and older) COVID-19-related consults at the emergency department of UP-PGH. Patients who went home against medical advice or those who did not complete treatment at PGH were excluded from the study. Data extracted from the hospital records included: admission date, case number, patient's demographic characteristics (age, sex, nationality, place of residence), chief complaint, associated symptoms at the ED (e.g., fever, respiratory symptoms), history of travel, onset of symptoms (in days), category of COVID-19 (suspect, probable, confirmed), presence of comorbidities, disposition at ED (admit, discharge, mortality), COVID laboratory result (positive or negative) and final outcome (discharge, mortality). Although case definitions were constantly updated, the following were used in this study based on the Department of Health (DOH) April 2020 Guidelines: ${ }^{8}$ (1) Suspect case - a person presenting with any following; (a) Severe Acute Respiratory Infections (SARI) cases where no other etiology fully explains the clinical presentation, (b) Influenza-like Illness (ILI) cases with no other etiology that fully explains clinical presentation AND a history of travel to or residence in an area with known local transmission 14 days prior to symptoms OR with contact to confirmed or probable in the 2 days prior to onset of symptoms of the probable/confirmed COVID-19 case until the time the they test negative with repeat real-time reverse transcription polymerase chain reaction (RT-PCR), (c) in aged 60 years and above, with comorbidity, assessed as having high-risk pregnancy or a health worker with fever or cough or shortness of breath or other respiratory signs and symptoms; (2) Probable case - a suspect case with inconclusive COVID-19 testing or those who tested positive but whose test was not done in a national or subnational reference laboratory or officially accredited testing center; (3) Confirmed cases - are those with positive RT-PCR for SARS-CoV-2 test result conducted at a national or subnational reference laboratory and/or DOH-certified testing facility. Underscoring the dynamic nature of the population at the ED, patients who came with COVID RT-PCR results or tests released during their ED stay have been classified accordingly as reflected in the "COVID-19 Category at ED." The "suspect," "probable" and "confirmed" category was based on the initial assessment at the ED following the $\mathrm{DOH}$ guidelines ${ }^{8}$ and only pertained to their status during their stay at the emergency department. Possible dispositions at the ED were discharge, admission or mortality.

Only cases with known information were included in the tabulation, precluding a thorough analysis of all the clinical characteristics of interest. Triage guidelines were regularly updated and hospital set-up was frequently changed during the initial stage of the pandemic depending on the 
available resources and manpower markedly impacting on the documentation of COVID cases. Some data were unavailable for a number of categories (e.g., comorbidities, COVID results, ED disposition, and final outcome) and recording of patient profile was not standardized.

Sociodemographic data and qualitative data were encoded in Microsoft Excel and analyzed using STATA Version 15.1. Categorical variables were reported as count (n), relative frequency or percentage and compared using $\chi^{2}$-test or Fisher's exact test when data was limited. For continuous variables, means and standard deviation, or median and ranges were computed. Ethical clearance for the study was granted by the UP-Manila Research Ethics Board (UPM-REB 2020-407-01) and adherence to data privacy and confidentiality was ensured.

\section{RESULTS}

A total of 901 Covid-19- related consults at the ED were included during the 6-month study period. Although the alerts of the new coronavirus came in from China as early as January 2020, no documented case was seen that month and only 1 COVID suspect case in February was recorded. The median age was 46 years with the youngest patient at 19 and the oldest being 91 . More than half were males (55.49\%) with most of the patients belonging to the less than 60 years age group. Almost all were Filipinos (99.44\%); majority resided in the city of Manila (64.93\%) and only 2.22\% had a history of travel outside the country prior to ED consult (Table 1).

The most common chief complaint was fever (32.5\%), followed by cough (27.6\%) and difficulty of breathing (25.8\%). On further examination of the patients at the ED, the commonly associated symptoms were cough (34.6\%) and difficulty of breathing (29.2\%). It must be noted that early on, staff and employees of PGH who had a history of contact with confirmed cases and by virtue of the likelihood of being exposed to possible COVID positives would develop minor symptoms but upon consultation at the ED they were symptom-free. They were still included in the chart review and were labelled "asymptomatic".

Around 76\% (688/901) were categorized as suspects on arrival at the ED, with majority having the onset of symptoms from 1-7 days (79.8\%), admitted to the wards (55.4\%) and turning out to be COVID-positive after performing the confirmatory test (86.1\%). Not all patient records indicated the presence of comorbidities, thus its actual coexistence cannot be ascertained. Only kidney and liver problems, cancer and heart failure were noted. A total of $89.7 \%$ were eventually discharged from the hospital either to their home, a quarantine facility or another hospital of choice (Table 2).

A higher proportion of patients with confirmed COVID were residing in Metro Manila compared to cities outside the NCR ( $p=0.046)$ and were either asymptomatic or complaining of fever on arrival at the ED (Fisher's exact test, $\mathrm{p}<0.001)$. The symptom onset $(\mathrm{p}=0.007)$, with $4-5$ days having
Table 1. Summary of general characteristics of patients with COVID-19-related consults at the UP-PGH ED $(\mathrm{N}=901)$

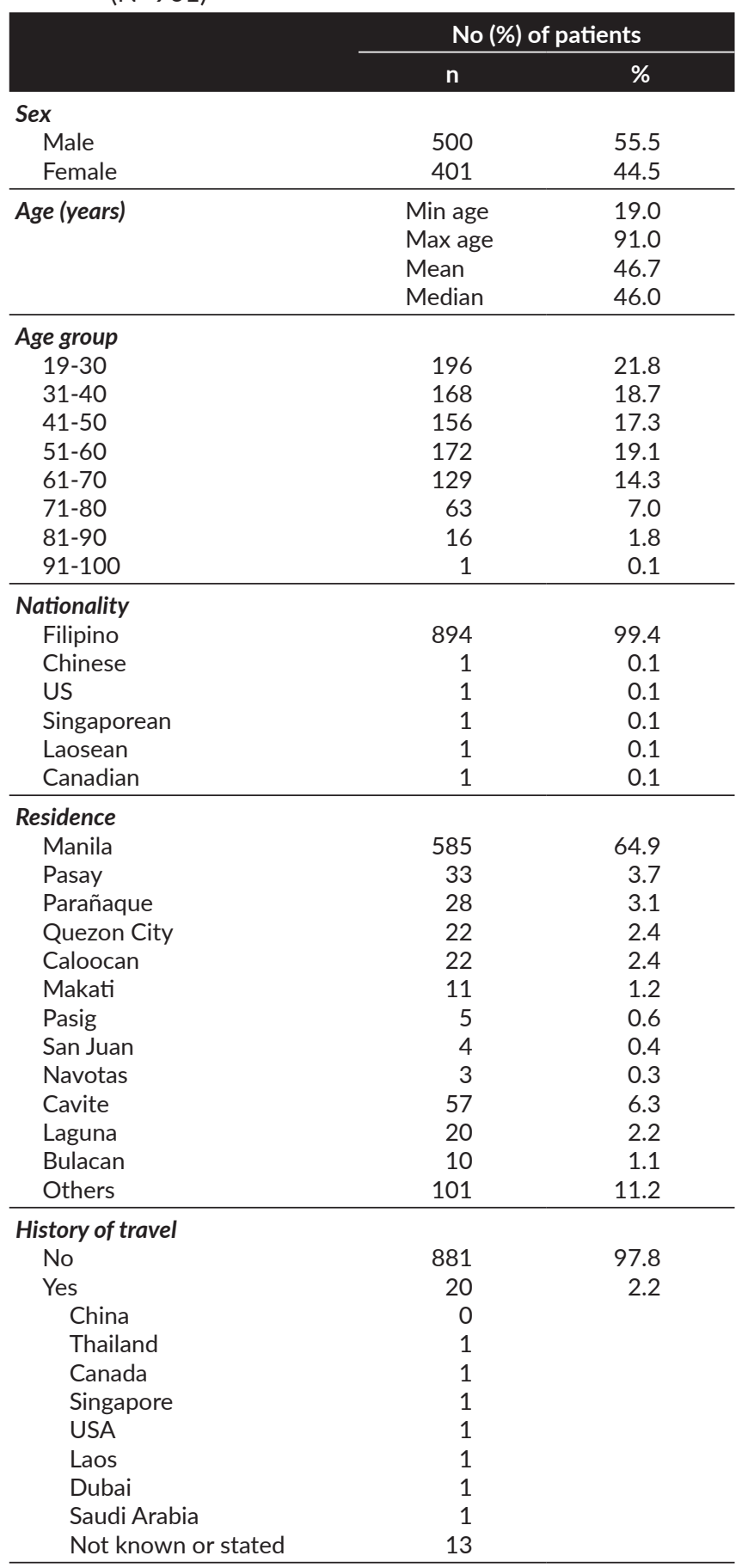

highest percentage (91.44\%) and being admitted $(\mathrm{p}<0.001)$ were significantly associated with a positive RT-PCR test (Table 3). From the available COVID laboratory results of patients with final outcome, 7 died out of 210 COVID-19 confirmed cases, resulting in a case fatality rate (CFR) of $3.33 \%$. The confirmatory COVID laboratory tests of the mortalities recorded at the ED could not be ascertained. 
Table 2. Clinical Characteristics and Final Outcome of COVID-19-related consults at the UP-PGH ED (N=901)

\begin{tabular}{|c|c|c|c|}
\hline \multicolumn{2}{|c|}{ Clinical Data } & $\mathbf{n}$ & $\%$ \\
\hline \multirow[t]{17}{*}{ Chief Complaint } & Fever & 237 & 32.5 \\
\hline & Cough & 201 & 27.5 \\
\hline & Shortness of breath & 188 & 25.8 \\
\hline & Sore throat & 37 & 5.1 \\
\hline & Weakness & 18 & 2.5 \\
\hline & Diarrhea & 16 & 2.2 \\
\hline & Coryza & 14 & 1.9 \\
\hline & Muscle aches & 9 & 1.2 \\
\hline & Headache & 7 & 1.0 \\
\hline & Fatigue & 1 & 0.1 \\
\hline & Loss of appetite & 2 & 0.3 \\
\hline & Asymptomatic & 40 & 5.5 \\
\hline & Others & 138 & 18.9 \\
\hline & Loss of smell & 0 & - \\
\hline & Loss of taste & 0 & - \\
\hline & Vomiting & 0 & - \\
\hline & Nausea & 0 & - \\
\hline \multirow{15}{*}{$\begin{array}{l}\text { Associated } \\
\text { symptoms }\end{array}$} & Cough & 134 & 34.6 \\
\hline & Shortness of breath & 113 & 29.2 \\
\hline & Coryza & 39 & 10.1 \\
\hline & Muscle aches & 27 & 7.0 \\
\hline & Sore throat & 25 & 6.5 \\
\hline & Diarrhea & 24 & 6.2 \\
\hline & Weakness & 15 & 3.9 \\
\hline & Fever & 4 & 1.0 \\
\hline & Fatigue & 3 & 0.8 \\
\hline & Headache & 2 & 0.5 \\
\hline & Loss of appetite & 1 & 0.3 \\
\hline & Loss of smell & 0 & - \\
\hline & Loss of taste & 0 & - \\
\hline & Vomiting & 0 & - \\
\hline & Nausea & 0 & - \\
\hline COVID-19 & Suspect & 688 & 76.4 \\
\hline \multirow{2}{*}{ Category at ED } & Probable & 9 & 1.0 \\
\hline & Confirmed & 204 & 22.6 \\
\hline
\end{tabular}

\begin{tabular}{|c|c|c|c|}
\hline \multicolumn{2}{|c|}{ Clinical Data } & $\mathbf{n}$ & $\%$ \\
\hline $\begin{array}{l}\text { Onset of symptoms } \\
\text { (days) }\end{array}$ & $\begin{array}{l}1 \\
2 \\
3 \\
4 \\
5 \\
6 \\
7 \\
8 \\
9 \\
10 \\
11 \\
12 \\
13 \\
14 \\
>14 \\
\end{array}$ & $\begin{array}{r}151 \\
113 \\
114 \\
81 \\
52 \\
66 \\
63 \\
22 \\
26 \\
17 \\
7 \\
4 \\
10 \\
19 \\
57 \\
\end{array}$ & $\begin{array}{r}18.8 \\
14.1 \\
14.2 \\
10.1 \\
6.5 \\
8.2 \\
7.9 \\
2.7 \\
3.2 \\
2.1 \\
0.9 \\
0.5 \\
1.3 \\
2.4 \\
7.1 \\
\end{array}$ \\
\hline Disposition at ED & $\begin{array}{l}\text { Admitted } \\
\text { Mortality } \\
\text { Discharge } \\
\text { Home } \\
\text { Hospital of choice } \\
\text { Quarantine facility }\end{array}$ & $\begin{array}{r}493 \\
22 \\
375 \\
318 / 375 \\
41 / 375 \\
16 / 375 \\
\end{array}$ & $\begin{array}{r}55.4 \\
2.5 \\
42.1 \\
84.8 \\
10.9 \\
4.3\end{array}$ \\
\hline Comorbidities & $\begin{array}{l}\text { Cancer } \\
\text { Heart Failure } \\
\text { Kidney Problem } \\
\text { Liver Problem }\end{array}$ & $\begin{array}{l}6 \\
6 \\
5 \\
2\end{array}$ & \\
\hline $\begin{array}{l}\text { COVID Result } \\
\text { (Overall) }\end{array}$ & $\begin{array}{l}\text { Positive } \\
\text { Negative }\end{array}$ & $\begin{array}{r}210 \\
34\end{array}$ & $\begin{array}{l}86.1 \\
13.9\end{array}$ \\
\hline Final outcome & $\begin{array}{l}\text { Discharge } \\
\text { Mortality }\end{array}$ & $\begin{array}{r}451 \\
52\end{array}$ & $\begin{array}{l}89.7 \\
10.3\end{array}$ \\
\hline
\end{tabular}

Compared to patients who were discharged $(n=451)$, those who died $(\mathrm{n}=52)$ were significantly older $(\mathrm{p}<0.001)$, with almost $20 \%$ more than 60 years of age. The chief complaint (Fisher's exact test; $\mathrm{p}<0.001$ ) and onset of symptoms $(p=0.037)$ have significant associations to final outcome. Of the deaths, approximately $35 \%$ had a presenting complaint of shortness of breath and $18 \%$ had symptoms for 6 days or more prior to ED consult. Sex, place of residence, and history of travel did not differ between patients who were discharged and those who died during hospitalization (Table 4). During the time of review, only known outcomes were included as the remaining unaccounted patients were still admitted and their final disposition could not be determined.

\section{DISCUSSION}

Real-time analyses of previous outbreaks vastly aided in providing much needed information on transmissibility, severity and natural history of an emerging pathogen. They are used in infectious disease modelling to generate and compare estimates for more rational intervention. Public

health-wise, findings from this research can form part of the surveillance to monitor future host adaptation, viral evolution, and pathogenicity.

The UP-PGH has been designated as one of the COVID-19 referral hospitals last 20 March 2020 and since then patients have been screened according to disease severity and acuity to prioritize admission of those requiring acute management. As knowledge of the disease during the first months was very limited, it was rather expected that $76.36 \%$ were categorized as suspects on arrival at the ED. The median age in this study (46 years) was similar to the reported median age in the early epidemiological analyses ${ }^{1,7,9}$ done in mainland China but lower compared to that of COVID-19 patients in Wuhan, China during the $1^{\text {st }}$ five months of the pandemic ( 57 years).$^{10}$ Haw et al. also reported a median age of 46 years, male preponderance $(53.8 \%)$ and 68.8\% living in the National Capital Region (NCR) among laboratory-confirmed cases from April-May 2020.11 Most published literature on COVID-19 consistently reported males being more affected than females. ${ }^{1,5,12}$ The weekly WHO COVID-19 Philippine situational report since April 2020 identify NCR having the most number of cases $^{13}$ as also shown in this study where majority reside in the city of Manila (64.9\%). The implementation of the community quarantine made it harder for other patients to seek consult at PGH due to lack of public transportation and establishment 
Table 3. Association of demographics and clinical profile to COVID-19 results

\begin{tabular}{|c|c|c|c|c|c|c|c|}
\hline \multirow{2}{*}{ Data } & \multirow{2}{*}{ Categories } & \multicolumn{2}{|c|}{ Positive result ( $n=210$ ) } & \multicolumn{2}{|c|}{ Negative result $(n=34)$} & \multirow{2}{*}{$\begin{array}{l}\text { Chi-squared } \\
\text { value }\end{array}$} & \multirow{2}{*}{ p-value } \\
\hline & & $\mathbf{n}$ & Row \% & $n$ & Row \% & & \\
\hline Age (years) & $\begin{array}{l}19-30 \\
31-40 \\
41-50 \\
51-60 \\
\geq 61\end{array}$ & $\begin{array}{l}30 \\
40 \\
37 \\
44 \\
59\end{array}$ & $\begin{array}{l}85.7 \\
83.3 \\
78.7 \\
88.0 \\
92.2 \\
\end{array}$ & $\begin{array}{r}5 \\
8 \\
10 \\
6 \\
5\end{array}$ & $\begin{array}{r}14.3 \\
16.7 \\
21.3 \\
12.0 \\
7.8 \\
\end{array}$ & 4.57 & 0.33 \\
\hline Sex & $\begin{array}{l}\text { Male } \\
\text { Female }\end{array}$ & $\begin{array}{l}110 \\
100\end{array}$ & $\begin{array}{l}84.0 \\
88.5\end{array}$ & $\begin{array}{l}21 \\
13 \\
\end{array}$ & $\begin{array}{l}16.0 \\
11.5\end{array}$ & 1.04 & 0.31 \\
\hline Residence & $\begin{array}{l}\text { Metro Manila } \\
\text { Others }\end{array}$ & $\begin{array}{r}158 \\
52\end{array}$ & $\begin{array}{l}88.8 \\
78.8\end{array}$ & $\begin{array}{l}20 \\
14\end{array}$ & $\begin{array}{l}11.2 \\
21.2\end{array}$ & 3.996 & $0.046^{*}$ \\
\hline Chief Complaint & $\begin{array}{l}\text { Fever } \\
\text { Cough } \\
\text { Sore throat } \\
\text { SOB } \\
\text { Asymptomatic } \\
\text { Others }\end{array}$ & $\begin{array}{r}65 \\
51 \\
5 \\
40 \\
40 \\
9\end{array}$ & $\begin{array}{r}91.6 \\
87.9 \\
83.3 \\
85.1 \\
100.0 \\
40.9\end{array}$ & $\begin{array}{r}6 \\
7 \\
1 \\
7 \\
- \\
13\end{array}$ & $\begin{array}{r}8.5 \\
12.1 \\
16.7 \\
14.9 \\
0.0 \\
59.1\end{array}$ & - & $<0.001^{*}$ \\
\hline History of travel & $\begin{array}{l}\text { Yes } \\
\text { No }\end{array}$ & $\begin{array}{r}2 \\
208 \\
\end{array}$ & $\begin{array}{l}66.7 \\
86.3\end{array}$ & $\begin{array}{r}1 \\
33\end{array}$ & $\begin{array}{l}33.3 \\
13.7\end{array}$ & $\begin{array}{l}- \\
-\end{array}$ & $0.364^{*}$ \\
\hline Onset of symptoms & $\begin{array}{l}1 \text { day } \\
2-3 \text { days } \\
4-5 \text { days } \\
\geq 6 \text { days }\end{array}$ & $\begin{array}{r}6 \\
52 \\
32 \\
80 \\
\end{array}$ & $\begin{array}{l}50.0 \\
85.3 \\
91.4 \\
85.1 \\
\end{array}$ & $\begin{array}{r}6 \\
9 \\
3 \\
14 \\
\end{array}$ & $\begin{array}{r}50.0 \\
14.8 \\
8.6 \\
14.9 \\
\end{array}$ & - & 0.007 \\
\hline Disposition at ED & $\begin{array}{l}\text { Admitted } \\
\text { Not Admitted }\end{array}$ & $\begin{array}{r}202 \\
8 \\
\end{array}$ & $\begin{array}{l}89.4 \\
44.4 \\
\end{array}$ & $\begin{array}{l}24 \\
10 \\
\end{array}$ & $\begin{array}{l}10.6 \\
55.6\end{array}$ & - & $<0.001$ \\
\hline Final outcome & $\begin{array}{l}\text { Discharged } \\
\text { Mortality }\end{array}$ & $\begin{array}{r}46 \\
7\end{array}$ & $\begin{array}{r}59.0 \\
100.0\end{array}$ & $\begin{array}{r}32 \\
-\end{array}$ & $\begin{array}{r}41.0 \\
0.0\end{array}$ & - & $0.042^{*}$ \\
\hline
\end{tabular}

${ }^{*}$ Fisher's exact test

Table 4. Association of demographics and clinical profile to final outcome

\begin{tabular}{|c|c|c|c|c|c|c|c|}
\hline \multirow{2}{*}{ Data } & \multirow{2}{*}{ Categories } & \multicolumn{2}{|c|}{ Discharged $(n=451)$} & \multicolumn{2}{|c|}{ Mortality $(n=52)$} & \multirow{2}{*}{$\begin{array}{c}\text { Chi-squared } \\
\text { value }\end{array}$} & \multirow{2}{*}{ p-value } \\
\hline & & $\mathbf{n}$ & Row \% & n & Row \% & & \\
\hline Age (years) & $\begin{array}{l}19-30 \\
31-40 \\
41-50 \\
51-60 \\
\geq 61 \\
\end{array}$ & $\begin{array}{r}135 \\
105 \\
79 \\
62 \\
70 \\
\end{array}$ & $\begin{array}{l}95.7 \\
94.6 \\
89.8 \\
81.6 \\
80.5 \\
\end{array}$ & $\begin{array}{r}6 \\
6 \\
9 \\
14 \\
17 \\
\end{array}$ & $\begin{array}{r}4.3 \\
5.4 \\
10.2 \\
18.4 \\
19.5 \\
\end{array}$ & 21.848 & $<0.001$ \\
\hline Sex & $\begin{array}{l}\text { Male } \\
\text { Female } \\
\end{array}$ & $\begin{array}{l}254 \\
197 \\
\end{array}$ & $\begin{array}{l}91.0 \\
88.0 \\
\end{array}$ & $\begin{array}{l}25 \\
27 \\
\end{array}$ & $\begin{array}{r}9.0 \\
12.1 \\
\end{array}$ & 1.2823 & 0.26 \\
\hline Residence & $\begin{array}{l}\text { Metro Manila } \\
\text { Others }\end{array}$ & $\begin{array}{r}325 \\
12 \\
\end{array}$ & $\begin{array}{r}90.3 \\
100.0 \\
\end{array}$ & $\begin{array}{r}35 \\
- \\
\end{array}$ & $\begin{array}{l}9.7 \\
0.0 \\
\end{array}$ & 0.518 & $0.046^{*}$ \\
\hline Chief Complaint & $\begin{array}{l}\text { Fever } \\
\text { Cough } \\
\text { Sore throat } \\
\text { SOB } \\
\text { Asymptomatic } \\
\text { Others }\end{array}$ & $\begin{array}{r}85 \\
124 \\
37 \\
53 \\
37 \\
115 \\
\end{array}$ & $\begin{array}{r}85.9 \\
98.4 \\
100.0 \\
65.4 \\
100.0 \\
93.5 \\
\end{array}$ & $\begin{array}{r}14 \\
2 \\
- \\
28 \\
- \\
8\end{array}$ & $\begin{array}{r}14.1 \\
1.6 \\
0.0 \\
34.6 \\
0.0 \\
6.5 \\
\end{array}$ & - & $<0.001^{*}$ \\
\hline History of travel & $\begin{array}{l}\text { Yes } \\
\text { No }\end{array}$ & $\begin{array}{r}18 \\
433 \\
\end{array}$ & $\begin{array}{r}100.0 \\
89.3 \\
\end{array}$ & 52 & $\begin{array}{r}0.0 \\
10.7 \\
\end{array}$ & $\begin{array}{l}- \\
- \\
\end{array}$ & $0.24^{*}$ \\
\hline Onset of symptoms & $\begin{array}{l}1 \text { day } \\
2-3 \text { days } \\
4-5 \text { days } \\
\geq 6 \text { days }\end{array}$ & $\begin{array}{r}100 \\
123 \\
62 \\
108\end{array}$ & $\begin{array}{l}91.7 \\
90.4 \\
92.5 \\
81.8 \\
\end{array}$ & $\begin{array}{r}9 \\
13 \\
5 \\
24\end{array}$ & $\begin{array}{r}8.3 \\
9.6 \\
7.5 \\
18.2 \\
\end{array}$ & 8.50 & 0.04 \\
\hline
\end{tabular}

\footnotetext{
${ }^{*}$ Fisher's exact test
}

of multiple check points around Metro Manila. But of note is the province of Cavite having a considerable number of cases outside of NCR which has seen spikes since April 2020. ${ }^{14}$
The most affected were those aged 60 years and younger, accounting for $76.8 \%$ of the patients; the $19-30$ years age range had the highest percentage (21.8\%). In Hubei, China, initial 
analysis of COVID-19 cases up to February 2020, indicates that $87 \%$ of their confirmed cases were aged $30-79$ years and the overall case fatality rate was $2.3 \% \cdot{ }^{15}$ A Metro Manila hospital, during the initial period of the pandemic, reported individuals aged 60 and older were mostly diagnosed with the SARS-CoV-2 infection. ${ }^{16}$ Although incubation period could not be directly derived from our data, majority of patients in this cohort had onset of symptoms from 1-7 days (80\%), with only 13\% from 8-14 days. This parallels the estimate in 181 confirmed cases in Hubei, China from January to February 2020 that 101 out of every 10,000 cases ( $99^{\text {th }}$ percentile, 482) will develop symptoms after 14 days of active monitoring or quarantine with a median incubation period of 5.1 days $(95 \%$ CI, 4.5-5.8) and $97.5 \%$ will have apparent symptoms within 11.5 days (95\% CI, 8.2 to 15.6$)$ of infection. ${ }^{17} \mathrm{~A}$ review article for emergency physicians in March 2020 identified that the spread was usually from person to person by respiratory droplet within 6 feet with a mean incubation period of 5.2 days (95\% CI 4.1-7.0) that can range from 2 to 14 days. ${ }^{18}$ This also closely resembles the median duration of symptoms before admission of 7 days (IQR, 4-10 days) in Japan. ${ }^{19}$

Fever and cough together with shortness of breath (SOB) are the most common symptoms noted by patients, ${ }^{1,5,12,20,21}$ akin to the results of this cohort. Associated symptoms on further examination included coryza, sore throat, diarrhea and weakness, similar to most COVID-19 epidemiologic surveys. ${ }^{1,12,16,20}$ The percentage of asymptomatic patients in our study $(5.48 \%)$ is comparable to the COVID-19 Japan registry $(6.9 \%, 145 / 2113) .{ }^{19}$ Interestingly, the dysfunction in taste and smell frequently described as a feature during the initial phase of COVID $-19^{22,23}$ that usually preceded the respiratory symptoms ${ }^{24}$ were not exhibited by patients at the PGH-ED.

The hospital response to the pandemic during the early stage varied and was constantly updated. Detailed analysis of all general and clinical characteristics could not be carried out due to some missing data. Referral and triage guidelines, medical staff responsibilities and clinical algorithms continuously changed, which resulted in disparate documentation of patient medical data. Initially, the limited RT-PCR testing was prioritized for symptomatic patients or moderate and severe cases only. As a consequence, patients with mild symptoms and low likelihood of COVID-19 per history of exposure were either discharged home or sent to other quarantine facility without the benefit of the confirmatory test. Trends showing that confirmed COVID-19 cases mostly reside from cities in Metro Manila suggest that during the first 6 months of the coronavirus crisis rapid person-toperson transmission transpired in this region, which led to the imposition of the strict ECQ to abate further spread of the disease. ${ }^{25-27}$ Patients may have delayed consulting at the hospital mainly due to the suspension of public transportation and fear of being exposed to the infection, accounting for a rather late presentation of 4-5 days from onset symptoms to the ED. The CFR of $3.33 \%$ is consistent with the WHO weekly Philippine COVID-19 situational report proportion of deaths among confirmed cases of $3.4 \%$ last 30 June $2020 .^{28}$

It is expected that the cases seen and admitted at PGH were the critical patients needing tertiary care as it is one of the COVID-19 referral centers during the time of the chart review. Around 20\% deaths were in the age group of 60 years and older who complained of shortness of breath, similar to other reports. ${ }^{12,16,28}$ Delayed symptom presentation of 6 days or more, older age group, and presence of shortness of breath, were screening red flags for poorer prognosis that warranted more aggressive and urgent medical attention.

\section{Limitations of the Study}

The nature of this study, being a secondary data analysis, prevented the authors from gathering all needed information. The final COVID status was lacking in some charts due to the fact that nasopharyngeal swab testing was not done solely at $\mathrm{PGH}$ and numerous revisions in algorithms on referral and triaging resulted in incomplete and non-standardized documentation of clinical outcomes. Missing data on some categories (e.g., presence of comorbidities) precluded a conclusion on its trend or association with other variables. However, the fairly large number of patients included in the final analysis on other categories adequately described the clinical profile of patients during the early course of the disease. A single repository of a more robust, accurate and uniform recording of patient data and clinical information with adequate provisions for data security and privacy is recommended for easy retrieval and analysis. Lastly, the UP-PGH is a tertiary hospital that was designated as COVID-19 referral center midway in the study; hence, the type of patients included was skewed to the more severe cases. Caution is therefore advised in applying its generalizability to other COVID-19 patients from hospitals with different level of service capability and designation.

\section{CONCLUSION}

Armed with the knowledge of the local clinical features and demographic profile of emergency department consults of COVID-19, timely links can be mapped out and early patterns, if present, can be detected and addressed. During the initial phase of the pandemic, patients with confirmed COVID-19 mostly resided in cities of Metro Manila, either presenting with fever or asymptomatic but with high risk exposure and with 4-5 days onset of symptoms. Poor prognosis was associated with individuals aged 60 years and older, shortness of breath and with delayed symptom presentation of 6 days or more. These red flags will greatly help in achieving positive outcomes, through recognition of COVID-19 cluster areas and patterns of transmission, and addressing other public health concerns that may arise. Patient and clinical data analysis were not readily available during the initial stage of the pandemic in the country; the information gathered from this study can be used in improving 
awareness and a more rational diagnostic algorithm that are vital for first-line health workers during initial contact with suspected cases. Timely information will also benefit the hospital administration in proper allocation of funding, resources and manpower in response to a pandemic.

\section{Acknowledgment}

This study was given financial support under the 2020 UP-PGH COVID Research Grant for Medical Specialists/ Consultants. The funder had no influence in any aspect of the conduct of the research and the authors claim full responsibility for all data presented and the final manuscript.

\section{Statement of Authorship}

Both authors participated in the data collection and analysis and approved the final version submitted.

\section{Author Disclosure}

Both authors declared no conflicts of interest.

\section{Funding Source}

This paper was funded by the 2020 UP-PGH COVID Research Grant for Consultants.

\section{REFERENCES}

1. Huang C, Wang Y, Li X, Ren L, Zhao J, Hu L. Clinical features of patients infected with 2019 novel coronavirus in Wuhan, China. The Lancet. 2020 February; 395(10223):497-506.

2. World Health Organization. World Health Organization_Coronavirus disease (COVID-19) Pandemic [Internet]. 2020 [cited 2020 April]. Available from: https://www.who.int/emergencies/diseases/novelcoronavirus-2019.

3. World Health Organization. Listings of WHO's reponse to COVID-19 [Internet]. 2020 [cited 2021 February]. Available from: https://www.who.int/news/item/29-06-2020-covidtimeline.

4. Hu B, Zeng LP, Yang XL, Ge XY, Zhang W, Li B, et al. Discovery of a rich gene pool of bat SARS-related coronavirus provides new insights into the origin of SARS coronavirus. PLOS Pathogens. 2017 November; 13(e1006698).

5. Chen N, Zhou M, Dong X, Qu J, Gong F, Han Y, et al. Epidemiological and clinical characteristics of 99 cases of 2019 novel coronavirus pneumonia in Wuhan, China: a descriptive study. The Lancet. 2020 January; 395 (10223,):507-13.

6. Haagmans BL, Al Dhahiry SH, Reusken CB, Raj VS, Galiano M, Myers $\mathrm{R}$, et al. Middle East respiratory syndrome coronavirus in dromedary camels: an outbreak invetigation. Lancet Inf Dis. 2014; 14(2):140-45.

7. Sun K, Chen J, Vibaud C. Early epidemiological analysis of the coronavirus disease 2019 outbreak based on crowdsourced data: a population-level observational study. The Lancet. 2020 April; 2(4):E201-8.

8. Department of Health. Department of Health (2020) Administrative Order No. 2020-0013:Revised Administrative Order No. 20200012 'Guidelines for the Inclusion of the Coronavirus Disease 2019 (COVID-19) in the List of Notifiable Diseases for Mandatory Reporting to the DOH [Internet]. 2020 [cited 2021 February]. Available from: https://doh.gov.ph/sites/default/files/health-update/ ao2020-0013.pdf.

9. Guan Wj, Ni Zy, Hu Y, Liang Wh, Ou Cq, He Jx, et al. Clinical characteristics of Coronavirus disease 2019 in China. NEJM. February 2020; 382:1708-20.

10. Huang C, Huang L, Wang Y, Li X, Ren L, Gu X, et al. 6-month consequences of COVID-19 in patients discharged from hospital: a cohort study. Lancet. 2021 January; 397(10270):220-32.
11. Haw NJL, Uy J, Sy KTL, Abrigo MRM. Epidemiological profile and transmission dynamics of COVID-19 in the Philippines. Epidemiology and Infection. 2020 September; 148(e204).

12. Wang D, Hu B, Hu C, Zhu F, Liu X, Zhang J, et al. Clinical characteristics of 138 hospitalized patients with COVID-19 pneumonia in Wuhan, China. JAMA. 2020; 323(11):1061-9.

13. World Health Organization. COVID-19 in the Philippines Situation Report 13 [Internet]. 2020 [cited 2021 February]. Available from: https://www.who.int/philippines/internal-publications-detail/covid19-in-the-philippines-situation-report-13.

14. Department of Health. COVID-19 Tracker Philippines_Cases for Cavite, region IV-A: CALABARZON [Internet]. 2020 [cited 2021 February]. Available from: https://ncovtracker.doh.gov.ph/.

15. Novel Coronavirus Pneumonia Emergency Response Epidemiology Team. The epidemiological characteristics of an outbreak of 2019 novel coronavirus diseases (COVID-19). China CDC Weekly. 2020 February; 41(2):145-51.

16. Salva EP, Villarama JB, Lopez EB, Sayo AR, Villanueva AMG, Edwards T, et al. Epidemiological and clinical characteristics of patients with suspected COVID-19 admitted in Metro Manila, Philippines. Trop Med and Health. 2020 June; 48(56).

17. Laurer SA, Grantz KH, Qifang B, Jones FK, Zheng Q, Meredith HR, et al. The incubation period of Corona Virus Disease 2019 (COVID-19) from publicly reported confirmed cases: estimation and application. Ann of Int Med. 2020 March; M20-0504.

18. Chavez S, Long B, Koyfman A, Liang SY. Coronavirus Disease (COVID-19): A primer for emergency physicians. Am Jour of Emerg Med. 202024 March.

19. Matsunaga N, Hayakawa K, Terada M, Ohtsu H, Asai Y, Tsuzuki S, et al. Clinical epidemiology of hospitalized patients with coronavirus diesease 2019 (COVID 19) in Japan: report of the COVID-19 registry of Japan. Clin Inf Dis. 2020 September:1-13.

20. Lake MA. What we know so far: COVID-19 current clinical knowledge ad research. Clin Med. 2020; 20(2):124-7.

21. Pericas JM, Hernandez-Meneses M, Sheahan TP, Quintana E, Ambrosioni J, Sandoval E, et al. COVID-19: from epidemiology to treatment. Euro Heart Jour. 2020; 41:2092-108.

22. Samaranayake L, Fakhruddin K, Panduwawala C. Sudden onset, acute loss of taste and smell in coronavirus disease 2019 (COVID-19): a systematic review. Acta Odont Scand. 2020 August; 78(6):467-73.

23. American Academy of Otolaryngology-Head and Neck Surgery. AAO-HNS: Anosmia,hyposmia and dysgeusia symptoms of coronavirus disease [Internet]. 2020 [cited 2021 February]. Available from: https://www.entnet.org/content/aao-hns-anosmia-hyposmiaand-dysgeusia-symptoms-coronavirus-disease.

24. The Philippine Society for Microbiology and Infectious Diseases. Interim Guidance on the Clinical Management of Adult Patients with Suspected or Confirmed COVID-19 Infection (Version 3.1) [Internet]. 29 July 2020 [cited 2021 February]. Available from https://www.psmid.org/interim-management-guidelines-for-covid19-version-3-1/.

25. World Health Organization. COVID-19 in the Philippines Situation Report 16 [Internet]. 2020 [cited 2021 February]. Available from: https://www.who.int/philippines/internal-publications-detail/covid19-in-the-philippines-situation-report-16.

26. Department of Health. COVID-19 Tracker-NCR for Cases [Internet]. 2020 [cited 2021 February]. Available from: https://doh. gov.ph/covid19tracker.

27. Office of the Presdient of the Philippines, Official Gazette. Memorandum from the Executive Secretary On Community Quarantine Over the Entire Luzon and Further Guidelines for the Management of the Coronavirus Disease 2019 (COVID-19) Situation [Internet]. 2020 [cited 2021 February]. Available from: https://www. officialgazette.gov.ph/2020/03/16/memorandum-from-the-executivesecretary-on-community-quarantine-over-the-entire-luzon-andfurther-guidelines-for-the-management-of-the-coronavirus-disease2019-covid-19-situation/.

28. World Health Organization. COVID-19 in the Philippines Situation Report 42 [Internet]. 2020 [cited 2021 February]. Available from: https://www.who.int/philippines/internal-publications-detail/covid19-in-the-philippines-situation-report-42. 